Published online 2017 April 13.

Abstract

\title{
Imaging of Vascular Masses of the Head and Neck
}

\section{Mohammad Davoodi ${ }^{1,}$}

${ }^{1}$ Department of Radiology, Shariati Hospital, Tehran University of Medical Sciences, Tehran, Iran

"Corresponding author: Mohammad Davoodi, MD, Department of Radiology, Shariati Hospital, Tehran University of Medical Sciences, Tehran, Iran. E-mail: mohammaddavoodi47@yahoo.com

Received 2016 December 21; Accepted 2017 February 08.

\begin{abstract}
The classification and imaging appearances of vascular masses of the head and neck are reviewed. The radiological appearances of congenital vascular masses (infantile haemangiomas and other congenital vascular tumours, high-flow and low-flow vascular malformations), acquired vascular masses (benign and malignant tumours, non-neoplastic lesions) and other hypervascular masses are described and illustrated.
\end{abstract}

This is an abstract presented in the 33rd Iranian congress of radiology (ICR) and the 15th congress of Iranian radiographic science association (IRSA). 